\title{
Corrientes epistemológicas y sus implicaciones en la educación
}

\author{
Ana María Abad Salgado '
}

Recibido: 05-1 1-2019

Aceptado: 09-05-2020

\section{Resumen}

El presente artículo busca exponer los principios epistémicos del método científico a partir de Mario Bunge, dado que la epistemología sustenta los postulados de escuelas como la de Frankfurt -con sus principales exponentes: Adorno, Marcuse, Horkheimer, desde la visión del pensamiento crítico, y el pensamiento sobre el capitalismo- y la corriente epistemológica francesa - con sus exponentes: Michel Foucault, Gaston Bachelard y Louis Althusser-. Dichos postulados permiten dilucidar las implicaciones para la educación desde un saber crítico, por ser esta una actividad compleja en la que intervienen distintas variables: acciones, ideas, sentimientos, personas, objetos e instituciones.

Palabras clave: corrientes epistemológicas, postulados, educación. 


\title{
Epistemological lines and their implications for education
}

\begin{abstract}
This article seeks to expose the epistemic principles of the scientific method from Mario Bunge, given that epistemology supports the postulates of schools like that of Frankfurt - with its main exponents: Adorno, Marcuse, Horkheimer, from the perspective of critical thinking, and thinking about capitalism - and the French epistemological trend - with its exponents: Michel Foucault, Gaston Bachelard and Louis Althusser. These postulates allow us to elucidate the implications for education from critical knowledge, as this is a complex activity involving different variables: actions, ideas, feelings, people, objects and institutions.
\end{abstract}

Keywords: epistemological lines, postulates, education.

\section{Introducción}

La episteme surge de una estructuración de ciertas variables dadas en un periodo histórico, en los que se inserta la política, la economía, geografía, valores, costumbres, estructura social y socioeconómica, elementos que se relacionan sistemáticamente para crear marcos de referencia para interpretar los fenómenos sociales insertos en los procesos de interacción en que se desenvuelve el ser humano y en donde habrá indudablemente una praxis existencial y ética.

Existen realidades complejas que son cognoscibles, y la filosofía constituye una orientación en la elaboración de los modelos conceptuales para comprenderlas, para conocer sus estructuras y su funcionamiento. La función de la filosofía es ver las relaciones e 
interacciones de los paradigmas y postulados teóricos intrincados en la metodología y rigurosidad científica, pero con la rigurosidad del método científico, como fue planteado por Mario Bunge.

\section{Epistemología}

El proceso del conocimiento se ha ido constituyendo en la medida en que el ser humano-como ser pensante-, da respuesta a sus inquietudes y desarrolla técnicas para atender a las necesidades que el espacio y el tiempo le han ido presentando para la gobernabilidad y convivencia con el mundo, dentro del mundo para y con los del mundo; y diversas maneras que connotan una verdadera teoría del conocimiento.

En el método, la ciencia y su filosofía Mario Bunge, plantea que el conocimiento científico se basa en hechos específicos de la naturaleza y de la sociedad, el conocimiento es lógico y estructurado, lo que significa que no está constituido por sensaciones. El conocimiento científico está compuesto de pensamientos que siguen un patrón lógico para poder transformarse en ideas, estas se ordenan de tal manera que sea más fácil interpretarlas y así llegar a una conclusión lógica. Lo anterior permite esclarecer la manera como se origina el conocimiento y la relación sujeto-objeto que tiene lugar en el proceso investigativo. ¿Entonces cómo se da la relación sujeto - objeto? Esta relación se establece a partir del sujeto que capta su propia exterioridad de aquello que desea conocer, siendo esta la relación entre lo cognoscente, estableciendo los dos un proceso dialéctico a través del cual se capta la realidad.

El método de la ciencia se basa en la objetividad, se miran las cosas dejando de lado los sentimientos y emociones que se pueden relacionar al objeto de estudio, proceso en el cal los principios de la veracidad y la verificabilidad se pueden realizar al investigar hechos anteriores relacionados al objeto de estudio actual, y al probar a través de la experimentación y de los ensayos empíricos las hipótesis son formuladas. 
En este orden de ideas, la construcción de un modelo teórico que responda a la rigurosidad científica implica siempre una interrelación dialéctica entre el mundo que se le abre al científico/investigador y la manera como este responde y describe los fenómenos que analiza y presencia con empirismo ingenuo, apoyado en el tiempo cronológico, haciendo coincidir con cada modelo teórico los resultados en relación con sus preguntas de indagación(Gómez \& Ostos, 2018).

La metodología particular del método científico es siempre una construcción, en la que el pensador- filósofo convierte en método una condición ontológica, como lo es la de ser sujeto de lenguaje. Es posible reconocer procedimientos, etapas y pasos, que ayudan dentro del proceso en momentos de ordenamiento, interpretación y validación de la información, sin embargo, es improbable que exista un método para comprender, diferente a las posibilidades mismas del ser del investigador y filósofo al leer una realidad.

\section{Epistemología de las corrientes filosóficas}

La epistemología ocupa hoy, uno de los primeros lugares no solo porque pretende establecer las condiciones del conocimiento válido sino porque realiza un desmonte crítico de las teorías científicas, haciendo un análisis del método científico y asegurando la exactitud del conocimiento. La lógica de la investigación científica- expuso su visión sobre la filosofía de la ciencia abordando el problema de la ciencia y la metafísica, sus límites y criterios que permiten la distinción de las proposiciones científicas de las que no los son; por tanto, el investigador, como representante de la ciencia, realiza asociaciones entre las imágenes y los conceptos creando un modelo conjetural, que necesita ser argumentado.

Así, se estipulan la metodología de la investigación, paso a paso, que enmarca la elaboración categorial y los métodos y técnicas propias de la misma en su rigurosidad científica, y deben responder a los colectivos académicos y los discursos sociales en los que 
postula la filosofía y los juegos dialógicos (yo, tú, él, nosotros, etc.) de los que el investigador hace parte.

Las bases epistémicas impulsan el desarrollo de la ciencia, la cual se sustenta en postulados conceptuales, es así como la teoría crítica de la Escuela de Frankfurt se enfoca en la epistemología de la teoría social, cuyos postulados establecen comprensiones y abordajes a los problemas del hombre actual y a la interpretación de la historia y la realidad social.

En lo que compete a la Escuela de Frankfurt; la teoría crítica se propuso interpretar y actualizar la teoría marxista originaria según su propio espíritu. Por ello, entiende que el conocimiento no es una simple reproducción conceptual de los datos objetivos de la realidad, sino su auténtica formación y constitución. La teoría critica se opone radicalmente a la idea de la teoría pura que supone una separación entre el sujeto que contempla y la verdad contemplada, e insiste en un conocimiento que está mediado tanto por la experiencia, por las praxis concretas de una época, como por los intereses teóricos y extra - teóricos que se mueven dentro de ellas. (Osorio, 2007).

Teniendo en cuenta lo anterior, la teoría crítica plantea que el conocimiento está inmerso en la construcción propia del individuo con su entorno, tomando valor cognitivo su experiencia de vida y el punto de vista del conocimiento científico que le es significativo. No es un crecimiento crítico aquella información que le sea obliga a ser procesada sin su interés propio o ajeno a su voluntad.

\section{Exponentes de la epistemología francesa}

\section{Michel Foucaultt}

Pensador francés reconocido mundialmente por sus aportes en diferentes campos, como la historia, lenguaje, política, filosofía, economía, sexualidad y máquina del poder; se licenció en filosofía y psicología; nacido en 1926 en Francia en la ciudad de Poi- 
tiers, hijo y nieto de médicos, pero se opuso a seguir la tradición; fue estudioso de Nietzsche, profesor universitario de psicología e historia de la Psicología, también, impartió sus clases en escuelas normales.

Foucault, analiza el funcionamiento de los manicomios, de los asilos de ancianos, cárceles y en general se ocupa de la marginalidad social de los individuos; aspectos que lo llevan a redefinir las estructuras del poder aceptadas socialmente; un poder que está en la familia, las instituciones educativas, el Estado, en general, en todas sus instituciones, es una forma de dominación estructurada política y social; una de esas formas de dominación la ejercen las personas "normales" sobre los "anormales", pero además le da reconocimiento a la anormalidad y dice que solo reconociendo la anormalidad se sabe qué es lo normal.

Este autor criticó con argumentos sólidos, la forma de vigilar y castigar como medio de coacción y de exclusión. Foucault, se dedicó a analizar las diferentes formas de vida de las personas, incluso hablo de la verdad, la libertad, el lenguaje y "el análisis de los valores representativos de un sistema de representaciones, es decir, el análisis de éstas en función de un conocimiento- de un contenido de conocimiento o de una regla, de una forma de conocimiento" (Foucault, 2009, p. 19).

Algunas de sus obras son: Vigilar y castigar (1975), Las palabras y las cosas (1966), La arqueología del saber, (1969), Historia de la sexualidad, (1984), La arqueología del saber, (1969), Hay que defender la sociedad (1992) y su tesis doctoral: Historia de la locura en la época clásica (1961), entre muchos otros textos que incitan al lector a reflexionar lo cotidiano que, por ser rutinario, pasa inadvertido.

\section{Gastón Bachelard}

Emplea como pauta epistemológica la atención al trabajo científico, convirtiéndola en una práctica específica. Su revolución fi- 
losófica tiene en cuenta que las esferas del saber han producido normas de verdad en cada momento de la historia, postulado que compartía con autores como Canguilhem y Foucault.

Este planteamiento, así mismo destaca la dimensión artificial de las ciencias, que constituyen una forma de producción, además, de distinguir su carácter social. Por su lado, esa dimensión artificial es referida a la capacidad creativa por cuanto recurre a edificaciones simbólicas que configuran escenarios y definen formas de intervención en la práctica. Es importante mencionar, además, que, la creatividad de la ciencia nunca se puede desvincular de su historia, pues el sujeto de la ciencia se ve restringido por su historia y su contexto social.

Por otro lado, la epistemología propuesta por Bachelard no puede entenderse como una corriente clásica de la teoría del conocimiento, sino por el contrario, debe ser entendida en relación con los cambios que produce una conciencia o espíritu que busca refutaciones de los conocimientos anteriores a partir de la invención.

Así pues, el espíritu es visto para Bachelard como algo incompleto, por lo que lucha con él mismo siendo controversial y revolucionario debido a que el espíritu no pretende tener un arreglo, sino, una adaptación dentro del proceso histórico a las rupturas e invenciones, por lo que establece que, solo la razón dinamiza a la investigación, pues solo ella sugiere, más allá de la experiencia común (inmediata y especiosa), la experiencia científica (indirecta y fecunda). Es, pues, el esfuerzo de racionalidad y de construcción el que debe atraer la atención del epistemólogo.

El epistemólogo debe tomar los hechos como ideas, insertándolos en un sistema de pensamientos. Un hecho mal interpretado por una época sigue siendo un hecho para el historiador. Según el epistemólogo, es un obstáculo, un contra -pensamiento. Será, sobre todo, profundizando la noción de obstáculo epistemológico como se otorgará su pleno valor espiritual a la historia del pensamiento científico, (Bachelard, 2000, p. 20). 


\section{Louis Althusser}

Este pensador se propuso romper con la excepcionalidad de Marx y analizar sus aportaciones desde el punto de vista de una epistemología convencional. Un primer problema es que lo que Althusser entendía por epistemología convencional no es precisamente una perspectiva de consenso. Sus referencias en filosofía de la ciencia contemporánea eran casi exclusivamente los postulados de Bachelard $y$, en menor medida, de Canguilhem, cuyo trabajo - por otro lado, muy fecundo - quedó encapsulado en un contexto intelectual reducido.

Por eso, en ocasiones se ha propuesto absorber la intervención de Althusser en un espectro teórico más amplio, por ejemplo, cercano a un kantismo actualizado. Un segundo elemento importante de la obra de Althusser es la crítica de las filosofías de la historia evolucionistas. También en este caso interviene sobre un entorno conceptual de largo recorrido.

Es de resaltar que, tanto los herederos de Nietzsche de la tradición hermenéutica - desde Heidegger a Foucault - como los estructuralistas exigían una ruptura con el antropocentrismo filosófico moderno. Al mismo tiempo, distintas corrientes neohumanistas- desde Sartre a la Escuela de Frankfurt - reivindicaban a un Marx filosófico cuya principal aportación habría sido la crítica de la alienación. Althusser (1967) toma partido por la crítica estructuralista del historicismo y trata de reconciliar esta posición con las tesis de Marx; de ahí que, los textos althusserianos mezclan la reivindicación del marxismo con el análisis filosófico de normalización al marxismo, proponiendo una urbanización de esta teoría.

El antihumanismo de Althusser se suele resumir con el lema "la historia es un proceso sin sujeto" (Althusser, 1967 p. 75). Esto no significa, como a veces se mantiene, que la historia esté dominada por estructuras impersonales sino, sencillamente, que los hechos históricos no tienen un sentido inscrito en su propia naturaleza; es decir, no existe como lo expone Athusser una historia universal unitaria que se desarrolla con un sentido racional y coherente; esto 
puede sonar sonar sensato, pero lo cierto es que atenta contra una pre-comprensión de la historia que ha sido hegemónica en Occidente al menos desde san Agustín y que ha tenido una gran influencia en la historiografía (Karczmarczyk, 2011).

Al respecto se puede afirmar que, la historia universal es el proceso de desarrollo de un sujeto (la humanidad) - que va desplegando progresivamente sus características distintivas: el conocimiento, la racionalidad política, la virtud moral, el aumento de la capacidad productiva, la excelencia cultural. Los hechos históricos contingentes pueden ser catalogados, así, en función de su contribución a ese proceso evolutivo y, por tanto, recuperados para un relato general.

\section{Escuela de Frankfurt}

La Escuela de Frankfurt fue fundada en 1923 como instituto para la inversión social que respaldaba las teorías de los filósofos Marx, Weber y Freud, quienes daban respaldo a la teoría crítica social, que en su mayor contenido estaba fundada en la práctica que en la teoría. En 1933, con la persecución nazi, la escuela es trasladada a Estados Unidos. Esta corriente desarrolló en sus estudios un profundo análisis crítico de los valores y principios subyacentes en la sociedad moderna (la llamada "teoría crítica de la sociedad") que tendría amplio eco en los pensadores de la posguerra, desde Herbert Marcuse hasta Jürgen Habermas.

La Escuela de Frankfurt plantea conceptos políticos, económicos, sociales y psicológicos, organizados en teorías dialécticas con posibilidad de formular una crítica de la ideología capitalista. Esta corriente aportó contribuciones importantes al análisis de los individuos a través de la psicología; en este marco se encuadran los postulados de Adorno, Horkehimer y Marcuse, siendosus mayores exponentes desde 1930 hasta 1970.

Dicho tiempo sirvió a Horkheimer y Adorno para realizar una censura sobre la crítica denominada dialéctica negativa de la teo- 
ría industrial cultural, donde se expone cómo la cultura se vuelve un negocio para tener a los individuos como mercancías; además, estos pensadores realizan una crítica a la dialéctica de la llustración para conformar la conciencia capitalista basada en valores.

Al respecto, Marx es promotor de la dialéctica hegeliana para el entendimiento de la sociedad capitalista y de la evolución de la sociedad en el tiempo, dadas las diferencias entre la burguesía y el proletariado. Entre tanto, Freud imprime el concepto de enfermedad por patología del entorno social y biológico en las clases sociales oprimidas, llamada el capitalismo. Por otro lado, Weber demarca el concepto de sociología como ciencia que enfrenta la acción social con un enfoque del conocimiento.

A continuación, se describen los exponentes de la Escuela de Frankfurt:

\section{Theodor Ludwing Wisengrund Adorno}

Entre sus obras están:

1. Dialéctica de la llustración (1944), en la cual Adorno y Horkheimer, critican la época de la llustración, cuando se configura la conciencia capitalista a partir de los valores para crear una nueva conciencia del ser humano, siendo estos valores, su vez, expuestos como una barbarie, lo que llegan a plantear que el mito ilustrado es un callejón sin salida. Objetivo: saber por qué la humanidad desembocó en un nuevo género de barbarie. Respuesta: porque triunfó una forma de racionalidad.

2. Dialéctica negativa (1966). El primer concepto parte del reconocimiento del carácter contradictorio de la razón humana; la dialéctica negativa es representada como crítica y negación de la positividad y muestra que, el avance científico es en realidad un retroceso filosófico, ya que este avance se convierte en irracional, de modo que se postula lo que se conoce como la dialéctica negativa, ya que, dejando a salvo a la razón, se convierte en una crítica permanente, es decir, se convierte en una dialéctica en permanente revisión. 
3. Teoría estética: en esta obra, también muestra que existe una superestructura por encima de todo lo que se ha expuesto aquí, y esa superestructura es manejada por la burguesía, hecho que los lleva a pensar que en realidad es la burguesía la que maneja los hilos de las comunicaciones para que se cree una cultura de masas inexistente.

Este autor, muestra que en realidad la burguesía maneja los hilos para beneficiarse, es decir, si los burgueses son aquellos que tienen las fábricas, los comercios, lo que buscan es vender el producto final; por tanto, esta superestructura maneja los hilos de los medios de comunicación para crear una sociedad de consumo, creando al mismo tiempo falsas metas sociales, que normalmente tienen que ver con la economía, difícilmente alcanzables.

4. Mínima moralia: muestra el principio delos problemas morales, ya que expone una separación del trabajo, así como una división en los poderes establecidos; dicho de otro modo, unas clases sociales estamentales dependiendo todo de la riqueza acumulada y sus posesiones. También comenta Adorno, que en caso de pertenecer a la clase social establecida como alta, la estupidez, que es como llaman al desconocimiento, puede resolverse ganándose a los especialistas para conseguir sus objetivos.

En suma, Adorno no solo pretendía demostrar la falsedad del pensamiento burgués, quería demostrar que precisamente cuando el proyecto burgués - el proyecto idealista de establecer la identidad entre el pensamiento y la realidad material - fracasaba, era cuando demostraba, sin intención, la verdad social, probando entonces la preeminencia de la realidad sobre el pensamiento y la necesidad de una actitud crítica y dialéctica de no identidad hacia ella, probando, en otras palabras la validez del conocimiento materialista y dialéctico.

Entonces Adorno no hizo más que demostrar que era necesaria la actitud crítica dentro del pensamiento burgués, que pronto sería capitalista para rechazar todas las formas mercantilistas que se tejían para el ser humano desde las teorías de Marx, donde el hom- 
bre es deshumanizado en su concepto y despojado de su conciencia de hombre. Su pensamiento se inscribe dentro de la corriente dialéctica que define el pensamiento crítico del pasado siglo y, en concreto, a los integrantes de la Escuela de Frankfurt.

\section{Max Horkheimer}

Filósofo y sociólogo alemán que fue, junto con Theodor Adorno, uno de los principales representantes de la Escuela de Frankfurt. En conjunto con Adorno desarrolló las bases del pensamiento de escuela, como son las obras Dialéctica de la Ilustración, Fragmentos filosóficos y Crítica de la razón instrumental. Entre sus obras destacadas están:

1. Crítica de la razón instrumental o "Eclipse of Reason: en ella se contiene y expresa la misma mirada crítica y sumamente lúcida sobre la otra cara de la modernidad, sobre el precio que la humanidad va pagando por el avance imparable, y en absoluto inocente, del proceso moderno de racionalización.

2. Materialismo, metafísica y moral durante los años 30 Horkheimer, escribió una serie de ensayos sobre temas como autoritarismo y familia, materialismo histórico, cultura de masas y positivismo lógico. El tema central de estos fue la definición de la teoría como crítica de la ideología en bien de una sociedad más libre y racional.

\section{Herbert Marcuse}

Nació en Berlín, en 1898. Filósofo y sociólogo alemán. El pensamiento de Marcuse, fundamentado en elementos procedentes del marxismo y el freudismo, constituye una crítica de la sociedad industrial, cuyo carácter represivo y alienante acaba por someter a la clase obrera conformándola y convirtiéndola a su vez en explotadora indirecta de las clases marginadas de los países pobres. Su obra influyó en la formación de la llamada "nueva izquierda" estadounidense y lo consagró como el ideólogo de las revueltas estudiantiles de los años sesenta. Entre sus obras se destaca: 
1. El hombre unidimensional: Manifiesta que el hombre pierde su sentido crítico en la sociedad capitalista avanzada, convirtiéndose en un ser consumista y liberado de las costumbres, provocando adaptación e integración dentro de la sociedad, este postulado da paso al nacimiento de una democracia no liberal.

La sociedad planteada por Marcuse es positivista, como base de la racionalidad tecnológica y la lógica del dominio. Esta es una de las filosofías sin rival, dado que no permite la crítica y es un proceso revolucionario de las minorías; sugiriendo la eliminación de elementos utópicos de la cultura burguesa bajo el régimen del capitalismo totalitario. En definitiva, el carácter normativo puede orientarnos en una transformación racional de la realidad humana, porque representa índices de la historicidad consustancial a la realidad establecida; $y$, alcanzar el sentido de la pacificación de la existencia, que constituye el criterio marcusiano de progreso, dando paso al poder soberano frente a toda carga opresiva de los hechos; se entrevé la disertación teórica de Marcuse como una defensa de la ética frente a la tecnocracia. 
Figura 1. Postulados de la Escuela de Frankfurt.
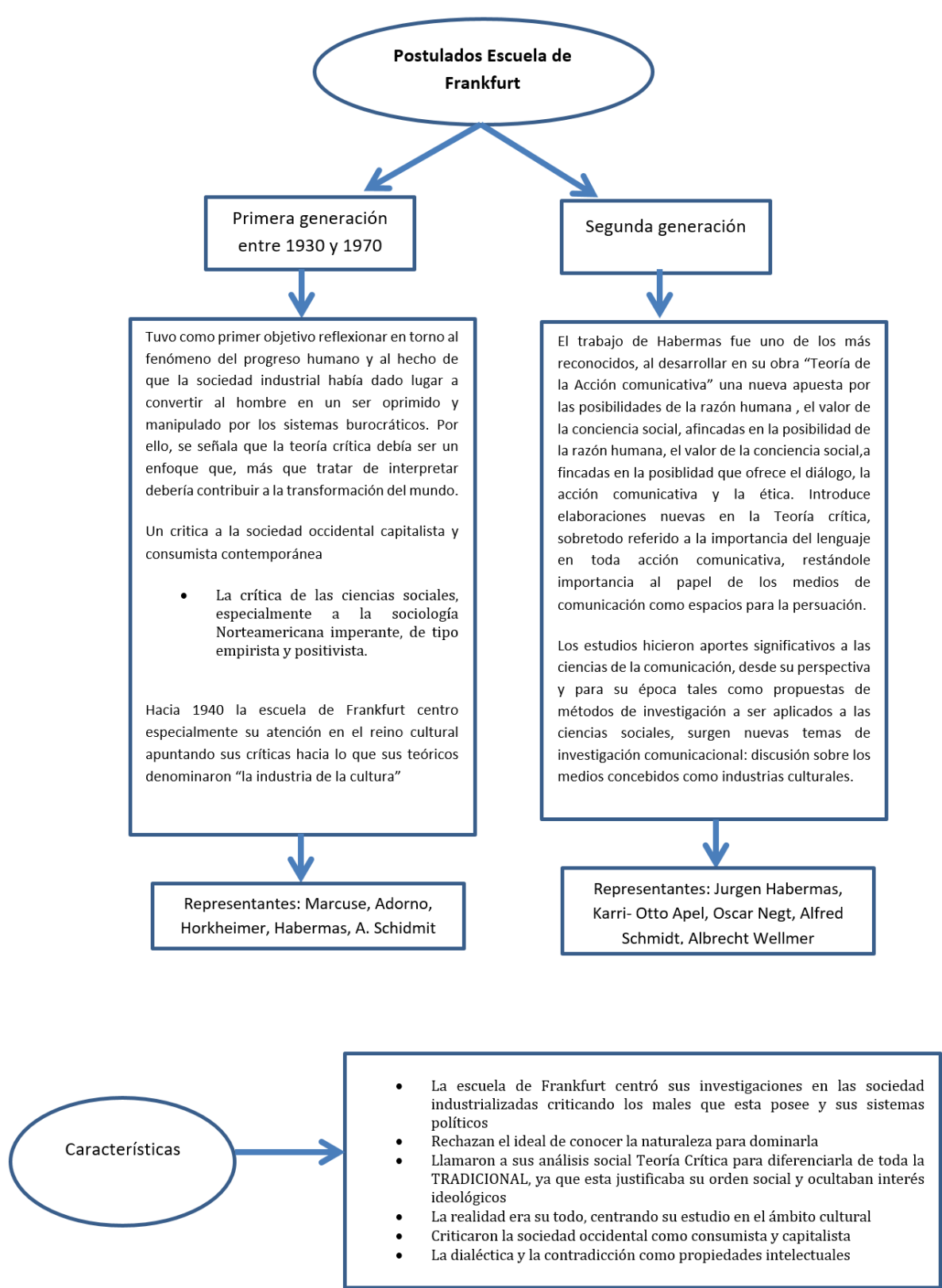

Fuente: elaboración propia. 
La epistemología ocupa hoy, uno de los primeros lugares no solo porque pretende establecer las condiciones del conocimiento válido sino porque hace un desmonte crítico de las teorías científicas, realizando un análisis del método científico y asegurando la exactitud del conocimiento como el fundamento de la educación, sistema que está llamado a comprender e intervenir las realidades humanas y sociales desde nuevas lecturas, análisis y discursos; por consiguiente, todo docente debe tener rigor epistémico para poder transitar por la polisemia científica preexistente y poder así mismo ser concordante con el objeto de estudio que va construyendo, en el proceso de disertación con los autores, referentes teóricos y marcos de referencia epistémicos.

Son muchos los elementos que el pensar epistémico brinda a los procesos educativos, no solo aporta la teoría del conocimiento para desarrollar un proceso investigativo sino también otorga elementos ontológicos y teleológicos que amplían la lectura de los contextos; a estos se puede llegar por medio de la enunciación de los términos que interrogan, los cuales a su vez son producto de un problema que acosa a los sujetos que buscan respuestas.

En consonancia con esto, es posible pensar el método científico soportado en la episteme, es partir de las reflexiones filosóficas que orientan las preguntas de ¿qué?, ¿cómo?, ¿por qué? y ¿para qué?, las cuales pueden dar luz a los investigadores, no solo como instrumentos de reflexión, sino también como ubicación dentro del mundo de los conocimientos, los cuales sirven para determinar el saber objetivo de los saberes cotidianos o vulgares; también son útiles para aclarar las intenciones de los investigadores - en coherencia con la pregunta que se pretenda plantear, lo mismo que para clarificar el objeto de investigación, que en ocasiones es enfrentado a ambigüedades propias del sujeto que quiere conocer o que está ávido de conocimiento.

A partir de los postulados epistémicos los docentes deben considerar el proceso educativo como un todo, es decir, integrar aspectos y actores presentes en el acto de educar, que se resignifica permanentemente por la interacción de todos los implicados, 
nuestro pasado, nuestros sueños, nuestra propia interacción con las interacciones de los otros; y los otros nos hacen y nos definen una manera particular de ser y hacer como maestros. Es interesante observar desde allí porque ofrece consciencia del nosotros y del otro y por tanto invita a la posibilidad.

De este modo se puede exponer, que las corrientes epistemológicas contextualizan nuevas formas de aprendizaje, ya que existe el concepto de inteligencias múltiples, conceptos que demarcan la diversidad y la inclusión que connota otras formas de relación, como las que se establecen entre docente y estudiante en el marco de la educación.

\section{A modo de conclusión}

El pensamiento filosófico está intrínsecamente relacionado con el pensamiento científico y la generación de conocimiento que aporta al desarrollo social; es así como los postulados filosóficos que sustentan la ciencia son lo que hace posible la investigación científica. Ambas son importantes para poder comprender el entorno y el mundo en el que vivimos. En suma, la epistemología le permite al científico ampliar su visión sobre la investigación, ver con otra perspectiva su trabajo y adoptar un mejor enfoque al estudiar un tema(Gómez, Ostos, Gallego, \& García, 2019).

El enfoque epistemológico propone considerar la educación como generadora de procesos de formación hacia la gestión del conocimiento, relacionados con el contexto; esto implica pensar que las personas forman parte de sistemas más amplios, son determinadas por ellos y los determinan simultánea y recíprocamente. Por tanto, la educación es un fenómeno complejo que involucra diferentes actores, y procesos de investigación que se fundamentan en la epistemología de las corrientes teóricas y/o filosóficas.

El bagaje conceptual que otorga la filosofía es el fundamento epistemológico de la ciencia; como soporte investigativo a partir 
de la razón, el legado dejado por Mario Bunge desde una episteme científica influye en el conocimiento "moderno" que sigue sustentándose en la filosofía.

El sesgo analítico de la epistemología de la ciencia propia del positivismo concede a priori un importante lugar a la teoría, e invita al pensador, al filósofo y al investigador a leer la realidad no solo desde lo epistemológico sino desde lo contextual y cultural, que enmarca el legado histórico del conocimiento.

La teoría crítica y la dialéctica han sido pilares fundamentales de la Escuela de Frankfurt, para pensar el mundo desde la crítica de la evolución del mundo capitalista, dejando ver al hombre como inmerso en un mercado capitalista de compra y venta, pero capaz de repensar su sentido de vida y brindando la posibilidad de seleccionar su propio estilo bajo esquemas de emancipación y libertad.

El aporte de Adorno y Horkheimer lleva, además, a identificar las potencialidades de las fuerzas productivas del capitalismo que no quedan reflejadas en la clase obrera deficiencia del análisis marxista en la articulación social por clases; ellos encuentran una respuesta en la teoría de la refracción de la cultura, es decir, la teoría sobre las condiciones culturales en las que tiene lugar la integración social (Álvarez y Aramayo, 2006), que necesariamente inciden en la educación.

Se puede evidenciar que, el conocimiento crítico ha venido en ascenso en pro de hacer una reflexión frente a la sociedad, sus estadios y, especialmente, el ser humano como protagonista; muestra de ello, es el principio de los problemas morales, del que habla Adorno en su obra Mínima moralia, en la que hace relación de una separación del trabajo, así como de una división en los poderes establecidos, es decir, unas clases sociales estamentales, sistema que depende todo de la riqueza acumulada y sus posesiones. 


\section{Referencias bibliográficas}

Althusser, L. (1967). La revolución teórica de Marx. Madrid: Siglo XXI.

Álvarez, J. \& Aramayo, R. (2006). Disenso e Incertidumbre: un homenaje a Javier Muguerza. Madrid: Plaza y Valdés.

Bachelard, G. (2000). La formación del espíritu científico. Buenos Aires. Siglo XXI.

Bunge, M. (1984). El método, su método y su filosofía. Buenos Aires: Universidad de Buenos Aires.

Foucault, M. (2009). El gobierno de sí y de los otros. Recuperado de https://monoskop.org/images/7/78/Foucault_Michel_El_gobierno_de_ si_y_de_los_otros.pdf.

Karczmarczyk, P. (2011). Materialismo, ideología y juegos de lenguaje, en Calletti, S; Romé, N y Sosa, M. (2011). Lecturas de Althusser. Proyecciones de un campo problemático. Buenos Aires, Imago Mundi.

Osorio, S. (2007). La teoría crítica de la sociedad de la Escuela de Frankfurt. Revista Educación y Desarrollo Social, 1(1), 92-105.

Gómez, O. Y. A., \& Ostos, O.-L. (2018). El constructivismo y el construccionismo. Revista Interamericana de Investigación, Educación y Pedagogía, RIIEP, 11(2), 115-120.

Gómez, O. Y. A., Ostos, O. L., Gallego, M. A. C., \& García, C. A. (2019). Análisis sistemático de los artículos publicados en la revista interamericana de educación, investigación y pedagogía (RIIEP) durante 2014 a 2019. Revista Interamericana de Investigación, Educación y Pedagogía, RIIEP, 12(2), 225-240. 